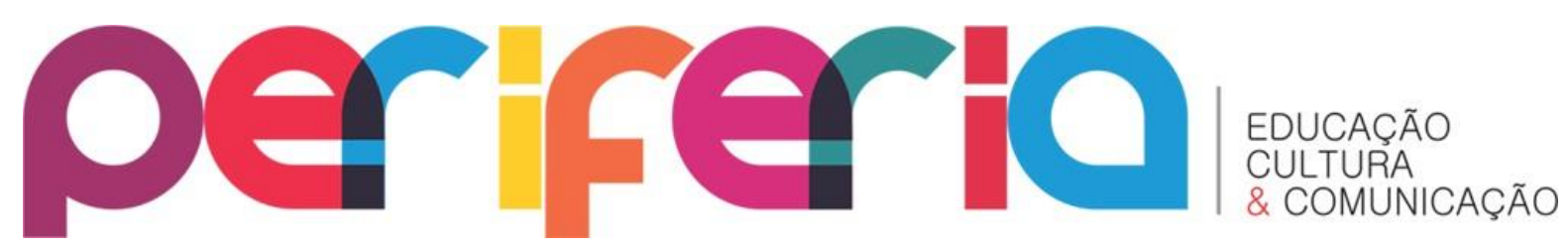

\title{
CURRÍCULO E PRÁTICA: TENSÕES QUE SE REVELAM NO CONTEXTO DA FORMAÇÃO
}

\author{
Neide Cavalcante Guedes ${ }^{1}$ \\ Universidade Federal do Piauí
}

\section{RESUMO}

O estudo objetivou compreender a relação entre o currículo e a formação que acontece nos estágios, considerando o eixo do curso de Pedagogia que é a formação de professores para a educação infantil e anos iniciais do ensino fundamental. 0 pressuposto é de que discutir o currículo conduz a uma reflexão sobre: Como o professor é formado? Como ele operacionaliza a prática? O campo empírico se constituiu de 25 alunos. O estudo é de natureza qualitativa cujo dispositivo de mediação foi o questionário onde os alunos expressaram angústias e tensões desse momento de conclusão da formação inicial. Os resultados evidenciam que as reflexões trazidas pelos alunos nos conduziram à apreensão de que a relação instituinte/instituído do currículo provoca conflitos e tensões que podem acarretar processos de institucionalização dinâmicos e únicos sendo, nessa perspectiva, que se opera a relação entre formação e currículo.

Palavras-chave: Currículo. Formação. Curso de Pedagogia.

\section{CURRICULUM AND PRACTICE: TENSIONS THAT ARE REVEALED IN THE TRAINING}

\section{ABSTRACT}

This study aimed to understand the relationship between the curriculum and the training that occurs in interships, considering the axis of the Pedagogy course which is teacher training for child education and the initial years of elementary school. The assumption is that discussing the curriculum leads to a reflection on: How the teacher is formed? How it operationalizes practice? The empirical field was composed of 25 students. The study is qualitative whith a questionnaire as the devide of mediation in which students expressed anxieties and tensions of this moment of conclusion of initial training. Results show that the reflections brought by students led to the apprehension that the relationship instituent / established curriculum leads to conflicts and tensions that can lead to dynamic and unique institutionalization processes. In that perspective operates the relationship between training and curriculum.

Keywords: Curriculum. Training. Pedagogy Course.

\footnotetext{
${ }^{1}$ Professora da Graduação e do Programa de Pós Graduação em Educação da Universidade Federal do Piauí. Coordena o Grupo de pesquisa Gestão, Currículo e Avaliação de Políticas Educacionais NUGCAPPE. Pesquisa também a Formação e a Prática docente. neidecguedes@hotmail.com
} 


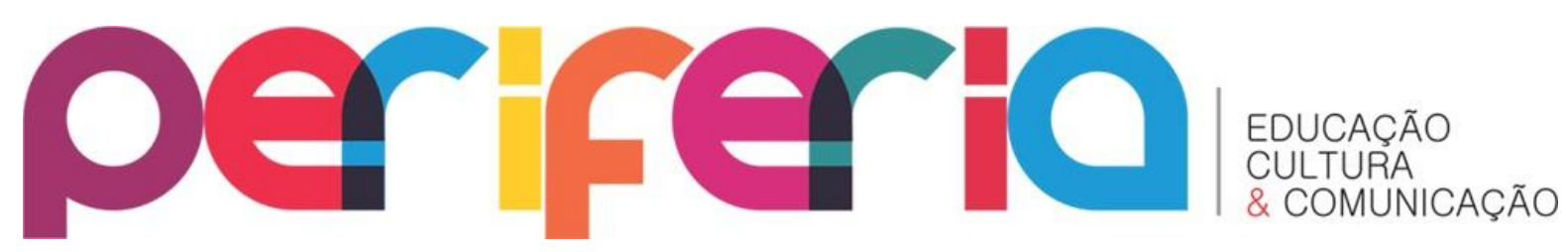

\section{INTRODUÇÃO}

As discussões sobre currículo estão em evidência no conjunto de documentos elaborados pelas escolas, bem como nas propostas apresentadas pelos diferentes sistemas que evocam uma compreensão de que se trata de uma construção permanente que deve estar conectadas com as exigências do mundo contemporâneo. Cada vez mais se compreende a importância do currículo na formação de novos educadores, qual na composição das políticas educacionais. Nesse sentido parto do pressuposto de que discutir o currículo conduz necessariamente a uma reflexão sobre: Como o professor é formado? Com base nesta formação como ele operacionaliza a sua prática?

Trabalhar o currículo a partir das necessidades de formação expressas pela humanidade é a possibilidade de garantir o poder agregador de bens culturais ao conhecimento o que faz com que tudo isso se reflita no contexto social mais amplo. Significa, conforme estabelece Moreira (2001) pensar o currículo e a formação em uma sociedade cada vez mais multicultural onde as culturas, etnias, visões de homem e de mundo penetrassem cada vez mais nos vários lócus.

Analisando de forma breve o contexto escolar brasileiro, é possível conferir a presença de práticas que além de promoverem a exclusão fazem uso, também, do poder discriminador que tem sistematicamente eliminado a identidades dos alunos originários de mundos culturais e sociais antagônicos e distantes do discurso hegemônico proferido pela sociedade e reproduzido pela escola (Canen \& Moreira, 1999).

A educação de acordo com Durkeim (1978) é um processo de criação e apropriação da cultura historicamente produzida pelo homem, onde a escola assume a condição de espaço privilegiado de produção e de transformação do saber sistematizado.

A ação de educar se reflete para fora do seu processo e é nesse espaço do mundo exterior que o seu sentido se completa. Pensar a educação implica pensar a

\section{v. 4 n. 1 jan-jul 2012}




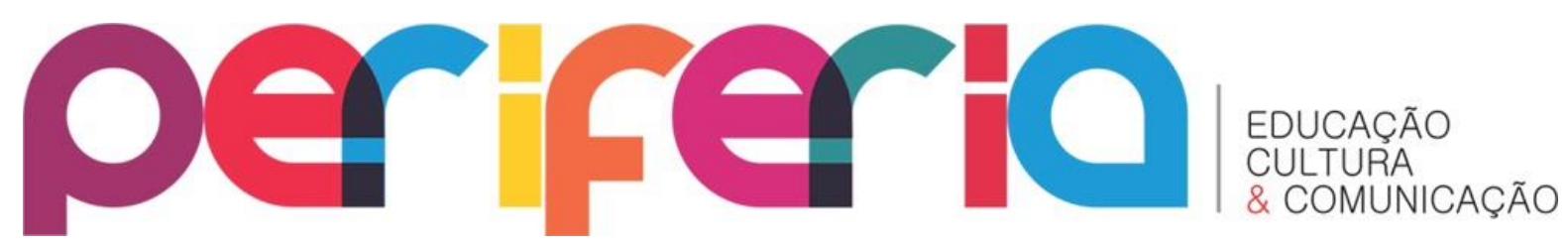

sociedade em que vivemos considerando o seu processo evolutivo e as diferentes concepções de homem manifestadas ao longo do processo de desenvolvimento da humanidade.

É, portanto, a partir do fenômeno educativo que se efetivam as transformações sociais e culturais necessárias ao ser humano, para que esse possa agir e interagir com seus pares, o que vai efetivamente caracterizar o processo educativo.

O trabalho docente é uma atividade consciente e sistemática que tem como centro o ensinar e o aprender, e nesse contexto o processo de organização e operacionalização da ação docente se efetiva a partir do planejamento que irá articular a atividade escolar de construção do conhecimento e sua articulaçao com o contexto social. Nessa configuração as teorias do currículo procuram justificar as escolhas dos conhecimentos e saberes, considerando as perspectivas tradicional, crítica e póscríticas.

A teoria tradicional concebe a escola semelhante a uma empresa e sua ênfase está na eficiência, na produtividade e na organização. Nessa perspectiva o currículo deve ser técnico e a educação um processo de moldagem.

O currículo tradicional centra-se na ideia de educação bancária criticada por Paulo Freire, ou seja, é um currículo que está afastado das pessoas que fazem parte do processo de aprender. Os especialistas em currículo tinham como tarefa fazer um levantamento das habilidades além de desenvolver um currículo que permitisse que essas habilidades fossem desenvolvidas. A questão principal da teoria tradicional diz respeito à junção de conteúdos, objetivos e o ensino desses conteúdos de forma eficaz para ter eficiência nos resultados. Por outro lado, a teoria crítica procura construir uma análise para entender não como se faz um currículo e sim compreender o que o currículo faz.

Giroux (1998) concebe o currículo como política cultural capaz de construir significados e valores tanto sociais quanto culturais.

\section{v. 4 n. 1 jan-jul 2012}




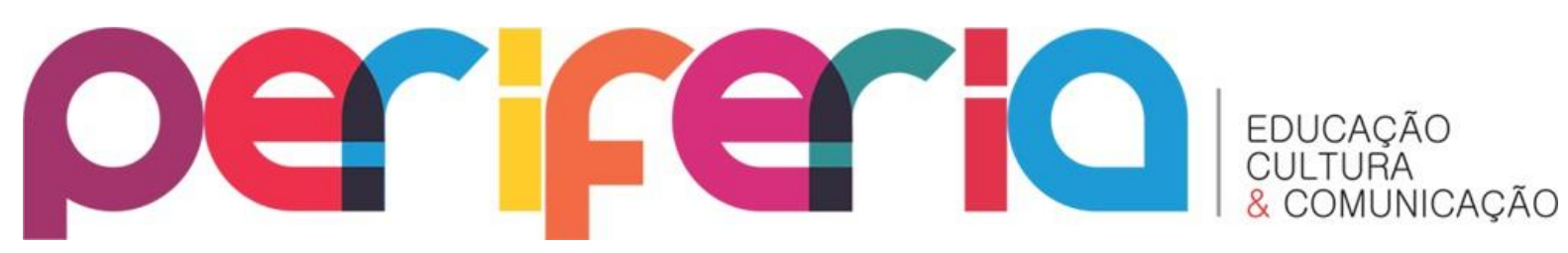

A educação, no seu contexto macro, estar a exigir dos professores, reflexões críticas nas quais seus conceitos e práticas estejam no centro dessas discussões tendo em vista que se torna imprescindível a instauração de mecanismos e contextos que favoreçam o desenvolvimento consciente desse processo, para que o professor possa, de fato, promover essa reflexão.

Como, então, deve-se constituir um currículo?

Tomando de empréstimo as ideias de Macedo (2007, p. 14), é possivel compreender que o currículo se expõe "[...] como um percurso no qual se cumprem trajetórias educativas e a educação culturalmente conjugada com o currículo nomeia, destina, põe e transpõe, funde edifunde outras possibilidades de pronúncia e escritura das imanências do educar".

Nessa perspectiva, a discussão entre formação e currículo levará em consideração as dimensões instituídas e instituintes da gestão curricular e que, portanto, o currículo é um texto em constante escrita. A relação instituinte/instituído do currículo gera conflitos e tensões que podem originar processos de institucionalização dinâmicos e únicos. Assim, o instituinte engloba forças que tendem a transformar as instituições, e esse movimento resulta em processos de produção, de criação, gerando, portanto, um produto, um resultado, sendo este o instituído.

As forças instituintes contribuem para construir - desconstruir relações existentes nas instituições, possibilitando desocultar questões que alterem ou dissolvam a naturalização de normas muitas vezes herméticas e desinteressadas, controladoras e propagadoras da submissão. Dessa forma enfatizamos o caráter relacional e construcionista do currículo como dispositivo educacional socialmente construído, no qual ganha forma o conceito de atos de currículo que, conforme Macedo (2010, p. 35)

Fazem parte da práxis formativa, trazem o sentido de não encerrar a formação num fenômeno exterodeterminado pela mecânica curricular e duas palavras de ordem, por consequência, não vislumbram os formandos e outros atores/autores da formação como 


\section{periferio}

meros atendentes de demandas educacionais, tão pouco aplicadores de modelos e padrões pedagógicos.

Essa perspectiva conceitual nos situa a não tratarmos as realidades antropossociais como produto de pessoas sendo avaliadas pelo que fizeram como indivíduos, mas focalizar nossas análises nas suas atividades para, assim, compreendermos a ordem social acontecendo.

O conceito de atos de currículo ganha valor nesse aspecto por se vincular a formação, constituindo uma maneira de resolução epistemológica para a compreensão da relação implicada entre currículo e formação pelo modo de empoderar o processo de democratização desse currículo como uma experiência que pode acontecer simultaneamente singularizada como um bem comum socialmente referenciado. 0 empoderamento acontece na medida em que se conquista e se distribui entre muitos o poder de realizar ações. Porém não é a mera realização de tarefas que define o empoderamento e sim a ação conectada a um senso de responsabilidade pelo trabalho, pela aquisição de conhecimento e pela capacidade de produzir mudanças a partir dele.

Assim podemos conceber o currículo e a formação entretecidos e implicados nos âmbitos da atividade, da intimidade e da negociação, por serem produzidos pelos atores e suas histórias, finalidades e interesses, bem como pelos segmentos sociais em estreita relação.

Portanto, a compreensão do processo instituinte do currículo se manifesta na dinâmica sócioformacional dos atos de currículo que é lugar de construções de hegemonias e reexistências, de processos híbridos, contextualizados e recontextualizados conforme suas necessidades.

Nesta linha de compreensão, o pressuposto sob o qual nos amparamos considera a avaliação como um procedimento de compreensão e acompanhamento da formação, considerando que a prática educativa se apresenta numa visão processual, relacional, sistêmica, complexa. A avaliação, nesse sentido, nos solicita uma 


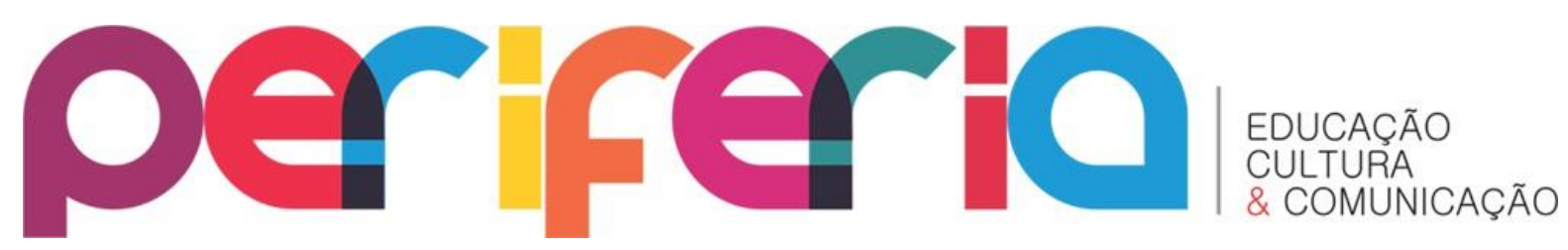

abordagem não fragmentada, não reducionista e não linear sustentando-se na emergência e na edificação da formação do sujeito humano na qualidade de aprendiz, ou seja, como assinala Macedo (2010. P, 204) "um Ser programado para aprender e condenado a aprender, nas suas itinerâncias e errâncias formativas".

A perspectiva mencionada se constitui na tentativa de superação dos modelos mecanicistas que tem predominado no campo da avaliação o que faz com que essa assuma a função de controle, fato que a tem transformado muitas vezes, numa prática burocrática.

Essa postura pode repercutir nos instrumentos de avaliação, ressaltando os sérios limites por ela enfrentados, uma vez que dificilmente se efetiva a avaliação na formação. Em geral, fazemos uso de instrumentos como provas, exames, averiguações, dentre outros, com a via ideal de controle dos resultados da aprendizagem, tendo em vista a burocracia presente na organização educacional.

Portanto, os termos pelos os quais concebemos a avaliação na formação implica numa visão, ao mesmo tempo, de totalidade sistêmica e genética capaz de superar a compreensão da avaliação somente vinculada aos objetivos instrucionais e institucionais.

Neste estudo procuramos entressachar os fios da formação e do currículo a partir de um estudo realizado com 25 (vinte e cinco) alunos do último período do Curso de Pedagogia da Universidade Federal do Piauí (UFPI), e deste total sorteamos aleatoriamente 10 (dez) alunos para compor a nossa amostra. Nossa intenção foi compreender como a relação entre o currículo instituído e a formação propriamente dita acontece e se manifesta nos contextos de estágios supervisionados, considerando que o referido curso tem como eixo principal a formação de professores para os primeiros anos do ensino fundamental e a educação infantil.

Nossas inquietações estarão direcionadas para o que denominamos de currículo em ação, ou seja, a reflexão e analise desse artefato se pautará naquilo que efetivamente já existe e se encontra institucionalizado no Projeto Pedagógico do

\section{v. 4 n. 1 jan-jul 2012}




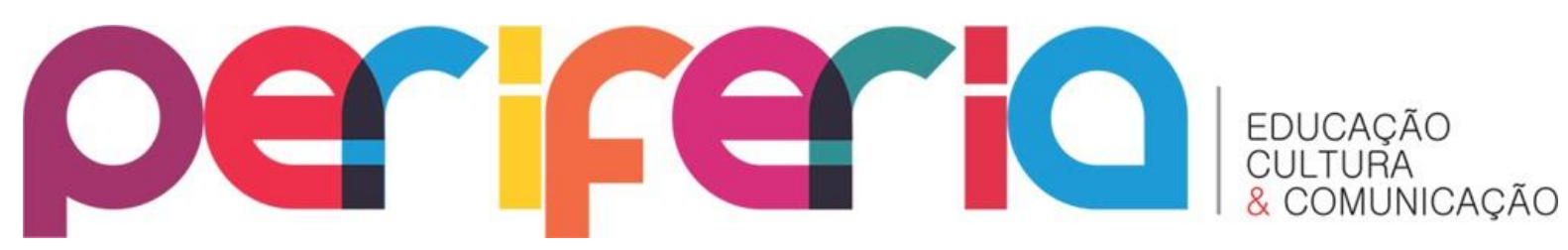

Curso. No entanto, não podemos descartar o que há de mais relevante nesse contexto que são, conforme enfatiza Macedo (2009), os atos de currículo que se traduzirão na dinâmica da prática educativa vivida por esses futuros professores. É, portanto, em Macedo (2009, p. 25) que buscamos uma melhor compreensão quando esse afiança que o currículo na condição de artefato educacional

[...] atualiza-se - os atos de currículo - de forma ideológica e, neste sentido, veicula "uma" formação ética, política, estética e cultural, nem sempre explícita (âmbito do currículo oculto), nem sempre coerente (âmbito dos dilemas, das contradições, das ambivalências, dos paradoxos), nem sempre absoluta (âmbito das derivas, das transgressões), nem sempre sólida (âmbito dos vazamentos, das brechas).

$\mathrm{Na}$ perspectiva metodológica o estudo se caracteriza como uma pesquisa qualitativa cujo dispositivo de mediação se constituiu de um questionário composto de questões abertas onde os alunos puderam expressar suas angústias e tensões originadas desse momento de conclusão da formação inicial. É no entrelaçamento dessas itinerâncias e errâncias, conforme assinala Macedo (2010), que vão se configurar os percursos formativos e, daí articulá-los ao currículo prescrito.

Considerando que a formação do futuro profissional docente se constrói no campo das tensões e contradições, tendo como arena o currículo instituído e instituinte, nossa pretensão é compreender os efeitos formativos que o currículo pode promover no sentido de garantir a formação necessária, cujo foco principal é as vivências e experiências que se evidenciam a partir das atividades realizadas no contexto da formação.

Esse currículo está desenhado no Projeto Político Pedagógico do curso que traz como áreas de formação a docência, nas dimensões da educação infantil e dos anos iniciais do ensino fundamental e a gestão educacional que, conforme o referido documento $(2009$, p.17) traça o perfil desse profissional do qual destacamos: (a) atuar na docência da educação infantil, nos anos iniciais do ensino fundamental e nas disciplinas pedagógicas em cursos de formação do profissional docente; (b) atuar no

\section{v. 4 n. 1 jan-jul 2012}




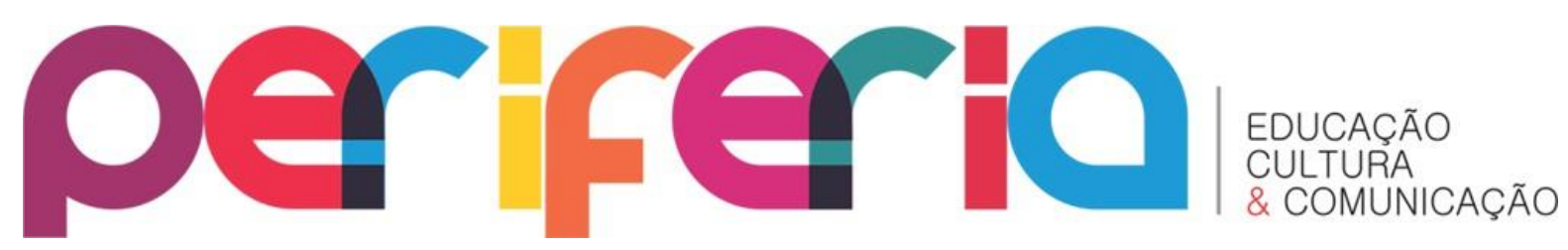

exercício da gestão educacional e de atividades gerais de assessoramento pedagógico como profissional técnico-pedagógico na escola e em outras instituições que desenvolvam ações educativas.

A partir das mudanças propostas no currículo do referido curso, é possível antever que o mesmo se encontra estruturado de maneira apropriada e capaz de garantir a análise dos aspectos contraditórios, seja no campo social ou cultural, seja no que diz respeito às políticas públicas como garantia da difusão do saber e da produção de novos conhecimentos no campo da ciência pedagógica.

As críticas feitas ao currículo, pelos alunos que estão no período de conclusão do curso, são direcionadas de forma mais efetiva aos conteúdos trabalhados no decorrer da formação e que deveriam garantir ao futuro profissional as condições necessárias ao pleno exercício de sua prática.

Segundo esses alunos, o currículo do curso de Pedagogia da UFPI da forma como vem sendo operacionalizado, não contempla plenamente o desenvolvimento das competências e habilidades que garantam sua atuação nos campos profissionais anunciados na proposta curricular vigente. Isso fica evidente quando, ao serem indagados quanto à adequação dos conteudos estabelecidos na Matriz Curricular trabalhados no decorrer do curso como necessários a formação do profissional pedagogo/docente, eles se manifestam:

Aluno E - considero boa, tendo em vista que durante o curso se discute o básico, ou seja, as disciplinas necessárias para a formação desse profissional, embora nao seja suficiente para enfrentar os dilemas que surgirão no ambiente escolar.

Aluno D - Avalio como deficiente, visto que nao contemplam aspectos relevantes à formação do professor para atuar nos níveis propostos pelo curso.

Aluno C - Regular, tendo em vista que as disciplinas sao fundamentais. No entanto precisamos associar teoria e prática, pois o âmbito escolar necessita de profissionais capacitados e competentes que saibam lidar com dificuldades inerentes a prática, 0 que muitas vezes deixa a desejar.

Aluno A - As disciplinas de metodologia não atendem as expectativas do alun, pois os professores ficam no nível da informação nao 


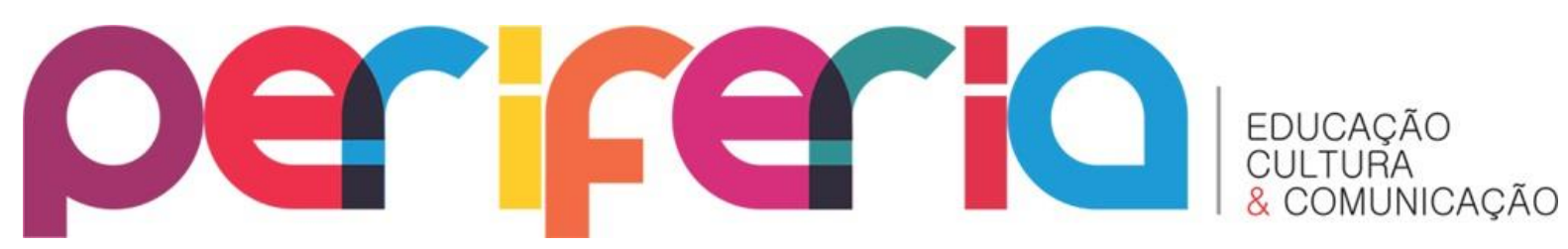

garantindo o exercício prática de como trabalhar o conteudo em sala de aula.

Aluno $\mathbf{N}-\mathrm{O}$ conjunto de conteudo é muito grande e repetido. Acredito que se fosse feito uma análise do todo em termos de currículo, boa parte das disciplinas seriam agregadas evitando a repetição de informações.

A partir das falas podemos inferir que o currículo do curso de Pedagogia apresenta fissuras que impedem uma melhor construção por parte do aluno provocando assim, lacunas que certamente se manifestarão no cotidiano da sua prática.

No que diz respeito às perspectivas das construções curriculares, Macedo (2007, p.33) vem nos dizer que "temos que proporcionar colisões entre os modelos e os sítios, com suas inteligibilidades situadas, individuais e coletivas, denominadas de etnométodos".

Essas colisões a que o autor se refere se constituem com base nas diferentes maneiras que as pessoas constroem a vida cotidiana, compreendem o mundo que as rodeia e solucionam os seus problemas, tendo como suporte seus saberes e as variadas formas de aprender. São, portanto, os modos, as configurações, os estilos como os atores sociais compreendem, movimentam e praticam suas ações, interpretando-as e descrevendo-as para todos os fins práticos.

Ao serem indagados quanto as disciplinas que dão sustentação a formação para atuar na educação infantil e nos anos iniciais do ensino fundamental e que serviram de apoio para a realização da prática de estágio, os alunos assim se expressaram:

Aluno A - Tento aliar isso através de um bom planejamento que é a base de qualquer aluno, mas o estágio obrigatório nem sempre proporciona experiencias boas para o aluno em formaçao.

Aluno B - Existem conteúdos que podem ser utilizados no estágio, mas a questão é adequar esse conteúdo à realidade da escola.

Aluno $\mathbf{H}$ - Relaciono de forma que a prática complementa a teoria e vice-versa. Porém, muitas vezes a forma como ingressamos no estágio nos leva a uma realidade diferente da teoria estudada.

Aluno E- É um aspecto ainda distante, uma vez que ao chegar na escola, no momento do estágio esta já se encontra organizada de forma que o aluno em formação não tem como demonstrar o seu aprendizado.

\section{v. 4 n. 1 jan-jul 2012}




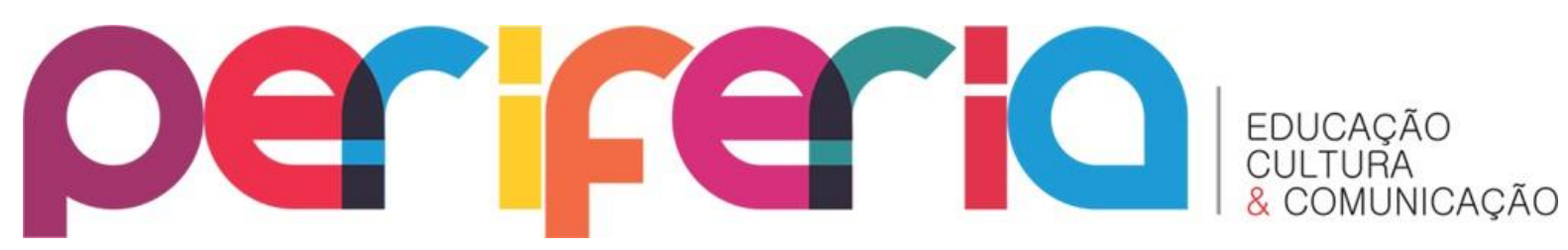

\begin{abstract}
Aluno $L$ - A dificuldade de aproximação entre o que se estuda na universidade e que se pratica na escola é muito grande, pois na maioria das vezes a gente vem pra escola com a teoria, e na primeira dificuldade que aparece a gente não sabe como lidar.
\end{abstract}

Com base nas colocações dos alunos, a forma e o volume de conteúdos trabalhados nas disciplinas direcionadas para a educação infantil e anos iniciais do ensino fundamental não atendem plenamente a necessidade da prática de estágio, e isso poderá repercutir de forma negativa no desenvolvimento da prática desse profissional.

Para melhor esclarecer nossos argumentos, nos apoiamos no pensamento de Macedo (2010, p. 61) quando afirma que "Os cenários educacionais, o conhecimento dito a priori, formativo, fundado na lógica disciplinar, vem sempre, de forma autoritária, na frente do conhecimento construido pela experiencia da formação".

Tomando como referência as palavras do referido autor e na busca de melhor compreender como efetivamente esse currículo instituinte se opera, indagamos junto aos alunos que esses relatassem uma situação vivida no decorrer do estágio e que percebeu não estar preparado para solucioná-la adequadamente.

Neste aspecto os alunos demonstram suas angústias e limitações tanto em termos de fundamentação teórica quanto em subsidios que poderiam está favorecendo a solução desses inprevistos tão comuns no campo da construção do conhecimento. Assim eles se expressam:

Aluno $\mathrm{E}$ - Eu me senti impotente frente a indiscipilina dos alunos pois não fui orientada nesse sentido.

Aluno G- Eu confesso que não me senti preparada para trabalhar com alunos portadores de necessidades especiais, isso porque as disciplinas que tratam desta questão ficam muito mais no nivel das discussões.

Aluno F - A minha experiencia aqui relatada é devido ao fato de não me sentir preparada para ministrar aula numa sala que tinha uma criança com problemas de iperatividade.

Aluno $\mathbf{L}$ - Ao iniciar o estágio nos anos iniciais do ensino fundamental eu me vi perdida, pois a realidade da escola é muito diferente daquela que construimos na universidade e isso cria um receio muito 


\section{periferio}

grande em relação as possíveis atividades que o estagiário pode desenvolver. Nós alunos não temos isso muito claro o que faz com que realizemos qualquer atividade na escola.

O que fica evidente, com base na fala dos alunos é que a formação do pedagogo emerge de um contexto cujas referências se voltam para diferentes campos do saber tais como a docência, a gestão e a pesquisa que são os grandes responsáveis em fundamentar pratica e teoricamente esse currículo.

Somente assim, será possível realizar a transposição didática, ou seja, a transformação dos saberes científicos em saberes submergidos pelos alunos do curso de Pedagogia, o que tem sido a grande dificuldade que esses enfrentam em seu processo formativo.

A transposição didática, conceito ampliado pelo pensador e educador francês Yves Chevallad (1991), se constitui de três partes distintas, mas interligadas: o saber do sábio (savoir savant) ou aquele que é elaborado pelo cientista; o saber a ensinar (savoir a enseigner), sob a responsabilidade dos professores, abrange a Didática assim como a condução da prática de sala de aula e o saber ensinado (savoir enseigné), saber absorvido pelo aluno após adaptações e transposições feitas pelos cientistas e pelos docentes (ALMEIDA, 2011). Ao considerar esses saberes distintos, mas conectados, Chevallad admite que há diferença entre o que é organizado no âmbito do conhecimento científico daquilo que advém do âmbito da educação.

Dessa forma, os alunos vivenciaram brechas em seu processo formativo, e essas levantaram questionamentos, inquietações e dúvidas que poderão gerar novas dinâmicas a serem trabalhadas no curso de Pedagogia. Referimo-nos aos não saberes da docência, ou seja, àquilo que os discentes deixaram de aprender durante a formação, como por exemplo, as dificuldades de lidar com as situações relacionadas à indisciplina, ou lidar com alunos portadores de necessidades especiais; e até mesmo, aquelas situações relacionadas à aplicabilidade dos conhecimentos construídos em sala de aula para serem utilizados na prática do dia a dia. Ou seja, embora se

\section{v. 4 n. 1 jan-jul 2012}




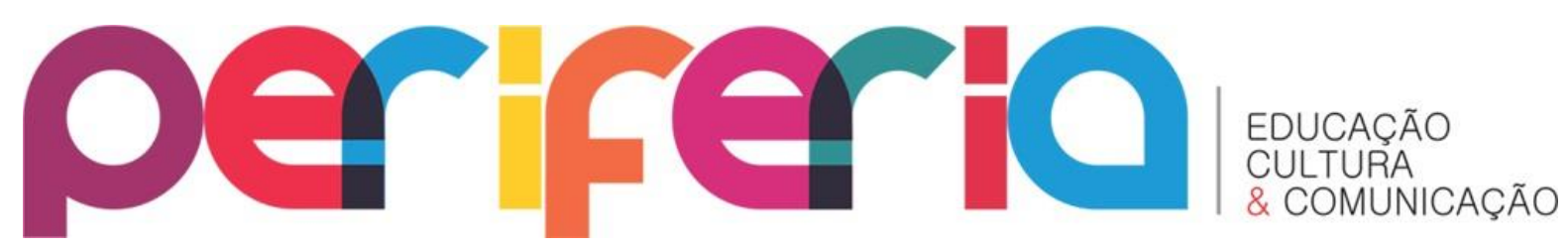

estabeleçam saberes do campo da profissão docente, certos conhecimentos deixaram de ser estudados e debatidos, por se constituírem em assuntos polêmicos ou tabus; sendo, dessa forma, silenciados no contexto da formação.

Enfrentar a necessidade de trabalhar os não saberes na formação nos conduz a aprender a conviver com a experiência da falta, com nossas limitações como seres humanos em processo de incompletude infinita. Devemos compreender que as brechas, as lacunas sempre nos perseguirão; e, certamente, nunca obteremos a totalidade do conhecimento. Ainda, assim, prosseguiremos a buscar respostas que suavizem a percepção de incompletude que nos é inerente.

Nesta perspectiva, Macedo (2007, p. 27) vai nos dizer que

[...] é bom que se criem mecanismos curriculares e atitudes formativas que possam enfrentar de forma mais realista a maneira com que os currículos filtram, selecionam, explicita ou tacitamente, ao buscar as maneiras de existir e competências que se ajustem ao seu ethos. É assim que a cultura hegemônica trabalha para legitimar ou deslegitimar, é por aí que nos encontramos ou não nas experiências curriculares é por estas vias que permanecemos ou não com nossos pertencimentos nas instituições educacionais, ou, nelas, assistimos à pasteurização das nossas referencias por não se enquadrarem no corpus ideológico dos saberes curriculares e suas formas de perceber e compreender o mundo.

Portanto, o liame tecido entre a Universidade e a Escola Básica, é muito importante e produtivo quando se reconhece, por um lado, a distância existente entre esses dois níveis de escolaridade; e, por outro, a não supremacia de uma instituição sobre a outra, evidenciando e acolhendo a contribuição que cada uma das instituições, dentro de sua especificidade, deve garantir no processo de formação do profissional docente.

Essa sintonia comprova a necessidade da articulação entre a teoria e a prática, em função da formação de professores, a fim de que o ensino na universidade não seja descontextualizado, mas enriquecido com a problemática do cotidiano escolar. E nem a prática da escola seja, somente, fruto do senso comum, ou uma prática ajustada pelo 


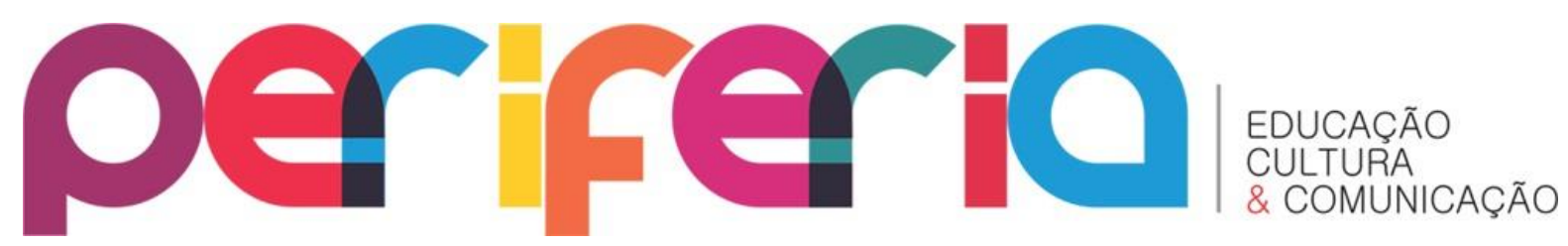

saber tácito, construído pela rotina, reprodução ou repetição das ações, mas resultado de uma ação crítica e reflexiva sustentada por um consistente referencial teórico.

Isso implica refletir sobre a formação como dimensão da atividade humana e, nessa perspectiva, ligada à mudança, a qual caracteriza fenômenos evolutivos e aparece como uma exigência de nossa época (MACEDO, 2010). Para melhor compreender, Honoré (apud MACEDO, 2010) ressalta quatro aspectos como fundamentais da formação:

$\checkmark$ A formação como direito do homem;

$\checkmark$ A formação como construção do desenvolvimento econômico e social;

$\checkmark$ A formação como aspecto aplicado das ciências humanas;

$\checkmark$ A formação como experiência reveladora das necessidades pessoais fundamentais.

As considerações dimensionadas nos remetem a reflexão de que estudar currículo no campo da educação significa considerar muitos mais os elementos subjetivos do que somente os conteúdos as metodologia que, em ação se constituem na prática cotidiana do professor.

Isso porque, o currículo instala-se nos espaços das disputas culturais, e aí se estabelecem as lutas entre distintos significados do indivíduo, do mundo, da sociedade, no processo de formação de identidades. Se esta compreensão do currículo nada retira à complexidade da relação entre individual e social, acaba por ressaltar o caráter ontológico da cultura, como definidora do indivíduo, na sua atividade reflexiva e na sua extensão biológica.

É nesse sentido que a importância da escola vai muito além, uma vez que é nesse espaço sistematizado que se entrelaçam fios no sentido de favorecer, além do exercício da cidadania, a compreensão das dimensões científica, técnica, ética e humana como componentes facilitadores da inserção do individuo no contexto social, promovendo a sua formação tanto na dimensão pessoal quanto profissional, constituindo-se a razão de ser de toda Instituição Escolar. Na perspectiva de Macedo

\section{v. 4 n. 1 jan-jul 2012}




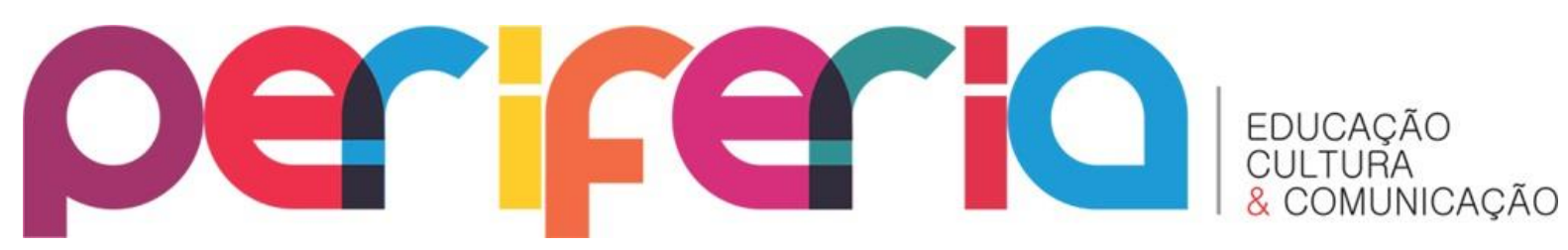

(2010), a formação envolve a autoformação, a heteroformação, a ecoformação e herosformação que se interligam para compor a transformação. A formação, sob esse ponto de vista, toma uma dimensão mais abrangente e profunda, posto que:

[...] se realiza na existência de um Ser social que, ao transformar em experiências significativas os acontecimentos, informações e conhecimentos que o envolvem e envolvem suas relações, nas suas itinerâncias e errâncias aprendentes, ao aprender com o outro, suas diferenças e identificações (heteroformação/transformação), consigo mesmo (autoformação), com as coisas, os outros seres e as instituições (ecoformação), emergirá formando-se na sua incompletude infinita, para saber-refletir, saber-fazer e saber-ser, como realidades inseparáveis, em movimento, porque constantemente desafiadas. Mediado pelos saberes da experiência, pela intuição, pelos afetos, pelas suas condições sociocognitivas, culturais e institucionais, poderá emergir qualificado ao aprender a aprender, a reaprender e a desaprender com os conteúdos históricos e das realidades que o desafiam, refletindo criticamente sobre a própria experiência formativa que vive (metaformação), aprendendo de forma implicada, portanto. (MACEDO, 2010, p. 50).

Assim, pensar em um currículo específico para o curso de Pedagogia requer que tomemos como ponto de partida o objeto fulcral da formação desse profissional pedagogo.

No entanto o que se ressalta é que as disciplinas são abordadas de modo reificado, como conteúdos estanques, com pouca ou nenhuma interconexão, tanto entre si, quanto em relação ao mundo concreto e à experiência vivida. Quando muito, desenvolve-se as práticas de trabalho de maneira mecânica, vazia de reflexão. Isto além de dificultar ao aluno uma compreensão mais abrangente do saber historicamente produzido pela humanidade colabora no reforço de uma visão quase que puramente tecnicista e instrumental que tem qualificado o ensino superior

Concordamos com Franco (2002) quando afirma que para o referido curso é necessário analisar o currículo tendo como suporte a perspectiva dialética no qual esse instrumento possa ser percebido como um projeto capaz de se transformar em cultura real e ser incorporado ao objeto do conhecimento que é o campo da Pedagogia. 


\section{periferio}

A cultura escolar configura o processo no qual o currículo se desenvolve, instituindo critérios de organização que acontecem a partir de categorias que constroem um tipo de escola e as possíveis ações a serem realizadas no interior dela. Se o currículo é uma opção da cultura, trata-se, portanto, de uma versão particular.

Essa particularidade se funda na relação currículo e cultura presente no processo de escolarização, na compreensão de que a cultura refere-se a conteúdos, práticas ou contextos extramuros da escola e, o currículo a conteúdos, práticas cotidianas e processos internos dessa escola. Assim, a cultura escolar é uma redefinição da cultura concretizada em razão das próprias condições nas quais a escolarização reflete modelos de comportamento, pensamento e organização.

Portanto, as reflexões trazidas pelos alunos nos conduziram à apreensão de que a relação instituinte/instituído do currículo provoca conflitos e tensões que podem acarretar processos de institucionalização dinâmicos e únicos. Assim, o instituinte junta forças que tendem a transformar as instituições, e esse movimento resulta em processos de produção, de criação, gerando, portanto, um produto, um resultado, sendo este o instituído. As forças instituintes colaboram para construir - desconstruir relações existentes nas instituições, permitindo descortinar questões que desviem ou dissolvam a naturalização de normas muitas vezes fechadas e abnegativas, controladoras e propagadoras da sujeição.

\section{REFERÊNCIAS BIBLIOGRÁFICAS}

ALMEIDA, Maria Doninha de (org). Licenciatura. 2ª Edição. Natal (RN), EDUFRN, 2004. ARAUJO, Hilda Mara Lopes. Processo identitário profissional: as experiências formativas de licenciandos do curso de Física - UFPI. 2011. 186 f. Tese (Doutorado) Programa de Pós-graduação em Educação, Centro de Ciências Sociais Aplicadas, Universidade Federal do Rio Grande do Norte, Natal, 2011.

CANEN, A. \& MOREIRA, A. F. B. Multiculturalismo, currículo e formação docente. Caxambu, 22a Reunião Anual da ANPEd, 1999.

CHEVALLARD, Y. La Transposición Didáctica: del saber sábio al saber enseñado. La Pausé Sauvage. Argentina, 1991.

\section{v. 4 n. 1 jan-jul 2012}




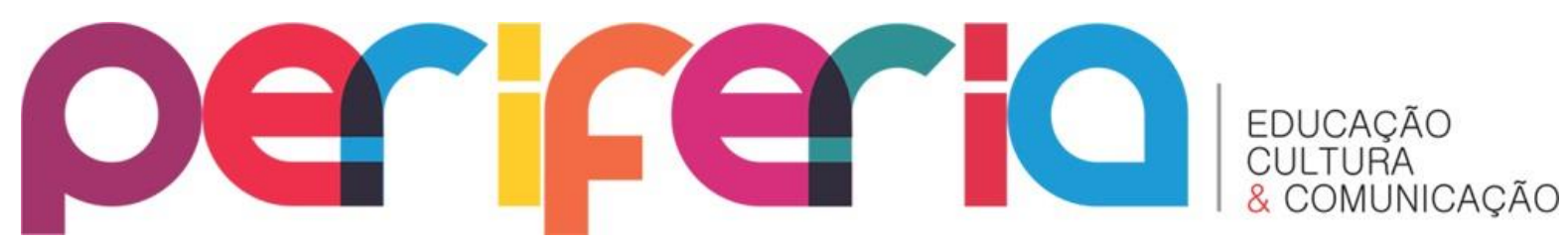

DURKHEIM, Émile. Educação e Sociedade. Ed. Melhoramentos. São Paulo, 1978

FRANCO, M. A. S. Para um currículo de formação de pedagogos: Indicativos. In: PIMENTA, S. G. (Org.). Pedagogia e pedagogos: caminhos e perspectivas. São Paulo: Cortez, 2002.

GIROUX, Henry. Os Professores como Intelectuais - Rumo a uma Pedagogia Crítica da Aprendizagem. Porto Alegre: Artmed, 1998.

MACEDO, Roberto S. Atos de currículo e formação: o príncipe provocado. IN: Revista Teias. Currículo: problematização em práticas e políticas. V. 13. № 27 jan/abril 2012. P.67-74

Atos de currículos formação em atos? para compreender, entretecer $e$ problematizar currículo e formação. Ilhéus (BA): Editus, 2011. Livro, 2010.

Compreender e mediar a formação: o fundante da educação. Brasília: Líber . Currículo: campo, conceito e pesquisa. Petrópolis (RJ): Vozes, 2009.

- A raiz e a flor. A gestão dos saberes para o desenvolvimento humano: inflexões multirreferenciais em currículo. IN: Revista do Núcleo de Currículo, Comunicação e Cultura. Salvador. V. 01, p.29-47, 2000.

MOREIRA, A. F. B. Currículo, cultura e formação de professores. Revista Educar. Curitiba, EDUPR, № 17, p. 39-52, 2001.

PIAUÍ. Resolução № 201/09 do Conselho de Ensino, Pesquisa e Extensão da UFPI CEPEX - aprova Proposta Curricular do Curso de Pedagogia da UFPI. Teresina, 2009. (Mimeografado). 